\title{
UNA APROXIMACIÓN GARANTISTA A LAS FUENTES DE LOS DERECHOS FUNDAMENTALES
}

\section{Introducción}

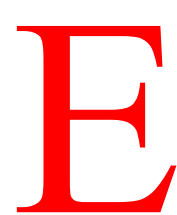

1 denominado sistema de fuentes de los derechos fundamentales propone diferentes niveles de aproximación teniendo en cuenta que, en esta materia, nos encontramos ante todo un «rompecabezas de datos constitucionales» ${ }^{1}$. Desde estas líneas, y dada la lógica limitación espacial a la que debe responder un artículo situado junto a otros numerosos autores que tienen la oportunidad de rendir un justo homenaje al profesor Elías Díaz, intentaré hacer un esbozo del acercamiento a dicho sistema de fuentes desde una perspectiva garantista. Entiendo que puede ser una sugerente fórmula, susceptible de ser recogida a la vista de la configuración constitucional de los derechos fundamentales. En este trabajo intentaré exponer cuales son los datos del esquema garantista de los derechos fundamentales.

Para ello es ineludible el planteamiento de una serie de problemas, que los especialistas consideran cuestiones no pacíficas, y el tratamiento de algunas de las claves para un adecuado enfoque de este tema. De lograr exponer con cierto orden este conjunto de elementos y su engarce en el sistema de fuentes de los derechos fundamentales, a la vista de los textos jurídicos, dependerá el alcance y coherencia de esta aproximación garantista.

\section{Aproximación a las fuentes desde los niveles de identificación de los derechos fundamentales}

En primer lugar contamos con la Constitución como primer texto por su jerarquía normativa respecto al conjunto del Ordenamiento

\footnotetext{
${ }^{1}$ En expresión significativa de Lorenzo Martín-Retortillo en la obra Régimen Constitucional de los derechos fundamentales. En L. Martín Retortillo e I. de Otto, Derechos fundamentales y Constitución, Civitas, Madrid, 1988, pág. 25.
} 
jurídico. Sobre su capacidad de vinculación el art. 9.1 de la Constitución española de 1978 (C.E. en adelante) afirma: «Los ciudadanos y los poderes públicos están sujetos a la Constitución y al resto del Ordenamiento jurídico». Numerosas sentencias del Tribunal Constitucional (TC en adelante) incorporan sus consecuencias bajo diferentes materias para reafirmar la capacidad de aplicabilidad directa de la C.E. de manera directa. Así la STC 21/1981, de 15 de junio reconoce al texto constitucional como «norma suprema directamente aplicable» y en STC 76/1983, de 5 de agosto la "capacidad de vincular al legislador», así como la STC 16/1982, de 28 de abril recoge la capacidad de ser «alegable directamente ante los tribunales». Sobre el valor normativo y su condición de texto directamente aplicable hay que considerar la trayectoria que en torno a la Constitución se ha mantenido sobre la materia. Además de las consideraciones generales que al principio de este trabajo hemos realizado sobre la ley y su visión decimonónica, hasta hoy llegan los ecos de interpretaciones no compatibles con las anteriores afirmaciones jurisprudenciales y del tenor del propio art. 9.1 de la C.E. Frente a ellas opiniones como la de Luis Prieto sintetizan el «iter» de dichas proyecciones: «Nuestra Constitución, aunque sin duda satisface esta función de «norma normarum», ha sabido recuperar también el verdadero significado de la idea constitucional, superando los planteamientos políticos decimonónicos, que concebían la Constitución como la norma reguladora de la vida»interna» del Estado, condición necesaria de la unidad del Ordenamiento, pero no fuente del Derecho en sentido propio». De ahí que la Constitución española quiera presentarse no sólo como fuente sobre la producción jurídica, sino como una auténtica fuente de derechos y obligaciones; norma jurídica que, además de fundamentar la unidad y validez del Ordenamiento, se integra resueltamente en él» ${ }^{2}$.

La visión anterior supone la directa capacidad que tendrán los derechos fundamentales incluidos en la Constitución (ya veremos que con diferente alcance dentro de la gradación que aparece en los diversos niveles del Título I) y de ello depende su enorme trascendencia. Serán normas de estructura o de competencia en la terminología de Bobbio $^{3}$ o normas secundarias en la terminología de

\footnotetext{
${ }^{2}$ Prieto Sanchís. L., El sistema de protección de los derechos fundamentales: El artículo 53 de la Constitución española, Anuario de Derechos Humanos, nº. 2, Madrid, 1983, pág. 380.

${ }^{3}$ Bobbio, N., Teoría General del Derecho, edición castellana de E. Rozo Acuña, Temis, Bogotá, 1987. Reed. en Debate, Madrid, 1991. Comprende dos trabajos de Bobbio: Teoria della Norma Giuridica, Giappichelli, Turín, 1958; y Teoria dell'Ordinamento Giuridico, Giappichelli, Turín, 1960, pág. 151.
} 
Hart ${ }^{4}$, dado que son preceptos que «que prescriben las condiciones y los procedimientos mediante los cuales se dictan normas de conductas válidas», ya que van dirigidas a los poderes públicos. Así el artículo 53.1 de la C.E. afirma: «Los derechos y libertades reconocidos en el Capítulo 11 del presente Título vinculan a todos los poderes públicos». Si entendemos estas normas secundarias de manera que permitan la conciliación con una fórmula mixta ${ }^{5}$, esto es, normas que puedan ser primarias ${ }^{6}$ en determinados aspectos por ser normas de conducta directamente dirigidas a los ciudadanos además de su condición de normas secundarias -o de estructura o competencia-, podemos asumir la dimensión compleja de los preceptos que regulan los derechos fundamentales. El análisis de su entramado en el texto constitucional nos permitirá estudiar el sistema de las fuentes de los derechos fundamentales y debido a ello, nos detendremos más adelante con mayor atención. Tan sólo adelantar aquí que el denominado sistema mixto ${ }^{7}$, caracterizado por regular los derechos

${ }^{4}$ Vid. Hart, H. L. A. El concepto de Derecho. Versión castellana de Genaro R. Carrio, Editora Nacional, México, 1980, pág. 99 y ss.

${ }^{5}$ No parece así en la definición de Bobbio. ya que el texto citado especifica previamente «aquellas normas que no prescriben la conducta que se debe o no observar, sino que prescriben las condiciones y los procedimientos mediante los cuales se dictan normas de conducta válidas». Obra citada, pág. 150.

${ }^{6}$ Son primarias en tanto que directamente establecen la conducta que puede ser tutelada en caso de no respetarse por los poderes públicos, y más discutidamente como veremos más adelante respecto a la Drittwirkung -la tutela frente a particulares-. El art.53.2 de la C.E. establece la tutela de las libertades y derechos reconocidos en el artículo 14 y la Sección $1^{\text {a }}$. del Capítulo II ante los Tribunales ordinarios «por un procedimiento basado en los principios de preferencia y sumariedad y en su caso, a través del recurso de amparo ante el Tribunal Constitucional. Este último recurso será aplicable a la objeción de conciencia reconocida en el artículo 30».

Hay que añadir que podemos entender que también cabe el doble recurso ante la jurisdicción ordinaria y ante la constitucional para el art. 30 merced a lo establecido por la Disposición transitoria segunda de la Ley Orgánica del Tribunal Constitucional que entiende que el ámbito de la Ley 62/1978, de 26 de diciembre de Protección Jurisdiccional de los Derechos Fundamentales de la Persona quedaba ampliado a todos los derechos y libertades reconocidos en el art. 53.2 de la C.E. Así la objeción de conciencia contaría con la protección del doble recurso ante ambas jurisdicciones además del recurso de amparo. Vid. en este sentido Prieto Sanchís. L., Estudios sobre derechos fundamentales, Debate, Madrid, 1990, pág. 106, nota $\mathrm{n}^{\circ} .21$.

${ }^{7}$ Término utilizado en el sentido de G. Peces-Barba en su obra Derechos Fundamentales, Latina Universitaria, (1 ${ }^{\mathrm{a}}$. ed. 1973), terc. ed. Madrid, 1980, págs. 138 y ss. Otra posible acepción, dentro de los modos de positivación de los derechos fundamentales de sistema mixto está en A. Pérez Luño, Los derechos fundamentales, Técnos, Madrid, 1984, pág. 58, cuando se refiere a grandes principios o postulados sobre los derechos fundamentales en los preámbulos de las Constituciones y el posterior desarrollo sistematizado en el articulado del texto constitucional. También alude al sistema mixto cuando la formulación de los derechos fundamentales se hace desde cláusulas o postulados generales junto a normas casuísticas o específicas. 
fundamentales a través de la doble vía de la Constitución y de leyes de desarrollo, permite hablar de normas secundarias en algunos casos que exigen su posterior desarrollo para poder convertirse en verdaderos derechos subjetivos con la tutela completa prevista para los derechos fundamentales, como es el caso de los principios rectores de la política social y económica, regulados en el Capítulo III del Título I ${ }^{8}$.

La tercera característica, relevante para la teoría de las fuentes es que además de emanar los derechos fundamentales de normas primarias y secundarias, es que nos hallamos ante verdaderas normas de identificación de carácter material. Esto es posible merced a su vinculación material respecto a los valores propugnados en el art. 1.1 de la C.E. -libertad, justicia, igualdad y pluralismo político-, de los que suponen un desarrollo, e igualmente respecto al punto de arranque de los derechos fundamentales en el artículo 10.1 de la C.E.: «la dignidad de la persona, los derechos inviolables que le son inherentes, el libre desarrollo de la personalidad, el respeto a la ley y a los derechos de los demás son fundamento del orden político y de la paz social». El Tribunal Constitucional pronto entendió los derechos fundamentales como prolongación del sistema de valores y principios. Así la STC de 15 Junio de 1981 afirma: «los derechos fundamentales responden a un sistema de valores y principios de alcance universal que (...) han de informar todo nuestro Ordenamiento jurídico» ${ }^{9}$.

Peces-Barba recoge los rasgos que el Ordenamiento jurídico debe mantener para que pueda acoger un sistema de derechos fundamentales en su seno y en el segundo de los rasgos aparece «una norma básica formal y material de identificación de normas, que señale los criterios de validez de éstas como pertenencia al Ordenamiento. Desde el punto de vista jurídico esta norma es la norma fundamental y suprema del sistema jurídico. En ella además de los criterios formales sobre quién manda, órganos competentes para la producción jurídica, y como se manda, procedimientos establecidos para esa producción, se fijan los criterios materiales, que se refieren a los contenidos de las restantes normas, a sus requisitos mínimos y a sus límites. Es la respuesta a la pregunta ¿qué se manda?» ${ }^{10}$. Desde esta

${ }^{8} \mathrm{Su}$ capacidad de «informar la legislación positiva, la práctica judicial y la actuación de los poderes públicos» que determina el art. 53.3, así como su posible aplicación directa en tribunales ordinarios, exige un posterior comentario que reconozca el alcance exacto de su reconocimiento, que más adelante veremos.

${ }^{9}$ Vid. el comentario que bajo el epígrafe «el alcance normativo de los derechos fundamentales formulados como valores y principios» hace Pérez Luño, en Los derechos fundamentales. Obra citada, págs. 61 y ss.

${ }^{10}$ Curso de Derechos Fundamentales (II). En colaboración con Rafael de Asís Roig y Ángel Llamas. En preparación, Cap. II, «El sistema jurídico de los derechos fundamentales: los rasgos de su identificación», pág. 3 del original. 
perspectiva los derechos fundamentales son un subsistema que mantiene los criterios de identificación material del sistema y de conformidad con Raz podemos entender «que la norma básica material concreta o identifica a las normas en dos sentidos, exigiendo criterios de dirección (guiding) o criterios de limitación (limiting). Los primeros señalan objetivos a conseguir y los segundos especifican peligros a evitar ${ }^{11}$. Los derechos fundamentales desde su formulación en los textos de las colonias americanas, desde la Declaración de Independencia de los Estados Unidos de América, en la génesis liberal que permite la Declaración de los Derechos del Hombre y del Ciudadano de 1789 y el posterior asentamiento en el Estado social y democrático de Derecho, han sido la expresión por un lado de los límites al poder, y superada la fase exclusivamente liberal y de sacralización de la ley, se han situado en sede constitucional en los ámbitos en los que se señalan precisamente los objetivos a seguir, dejándolos fuera incluso de las manos del legislador. Así responden adecuadamente a los criterios de limitación y de dirección exigidos por la norma de identificación material ${ }^{12}$.

El primer problema para conjugar esta aproximación con una descripción de las fuentes de los derechos fundamentales, se encuentra en delimitar claramente a qué nos referimos cuando hablamos de derechos fundamentales en la Constitución.

\section{¿Qué derechos fundamentales?}

Existen varias posiciones para establecer la extensión de los derechos fundamentales. Las diversas alusiones que aparecen en la Constitución a derechos, derechos fundamentales o derechos constitucionales hacen enfrentamos una primera dificultad. El epígrafe del Título Primero se denomina «de los derechos y deberes fundamentales», el correspondiente al Capítulo II, «Derechos y libertades», con la referencia del art. 53.1; el epígrafe de la Sección Primera del Capítulo II del Título I, «de los derechos fundamentales y de las libertades públicas», sobre el que se centra el art. 53.2, y la Sección II

${ }^{11}$ Raz, J., The Concept of a Legal System. An introduction to the Theory of a Legal System, Clarendon Press, 1' ${ }^{a}$. Ed., Oxford, 1970. Se maneja la reimpresión de 1983 correspondiente a la segunda edición de 1980. Hay versión castellana de R. Tamayo, U.N.A.M., 1986, pág.

${ }^{12}$ Vid. en el mismo sentido Juan José Solozábal Echavarría, Algunas cuestiones básicas de la teoría de los derechos fundamentales, Revista de Estudios Políticos, nº. 71, Enero-Marzo 1991, págs. 88 y s. En este artículo se repasa en diferentes niveles desde los que los derechos fundamentales funcionan como normas que cierran el sistema. 
del mismo capítulo que se refiere a los «derechos y deberes de los ciudadanos», situándose las garantías y las condiciones de la suspensión en los capítulos IV y V respectivamente, toda vez que el capítulo III está dedicado a esa especial clase de preceptos denominados «principios rectores de la política social y económica». En concreto el art. 149.1. I’. de la C.E. habla de la «regulación de las condiciones básicas que garanticen la igualdad de todos los españoles en el ejercicio de los derechos y en el cumplimiento de los deberes constitucionales», sin especificar estrictamente a qué derechos y deberes se refiere, o el art. 104.1 en el que las Fuerzas y Cuerpos de Seguridad deben «proteger el libre ejercicio de los derechos y libertades» sin concretar igualmente su sede. En ocasiones sí se acompaña la expresión a su localización, como el art. 13 cuando en referencia a los extranjeros entiende: «Las libertades públicas que garantiza el presente título», o con una residencia amplia en el art. 10.1: «Relativas a los derechos fundamentales y a las libertades que la Constitución reconoce», o el art. 86.1 «los derechos, deberes y libertades de los ciudadanos regulados en el título I». Las concreciones de los derechos fundamentales se sitúan de manera parecida con categorías de derechos diferentes; así la C.E. en el art. 9.3 habla de «derechos individuales», de «derechos políticos» en el art. 65.5, de «derechos inviolables que son inherentes a la dignidad de la persona» en el art. 10.1, de «derechos fundamentales y libertades públicas» en el art. 81, o de «derechos humanos» en su Preámbulo. En esta pluralidad de referencias el Tribunal Constitucional ha realizado una significativa y controvertida distinción entre derechos constitucionales y derechos fundamentales, Así la sentencia 160 /87 de 27 de Octubre, recurre a dos argumentos, uno formal y otro material para dejar fuera del carácter de derecho fundamental a la objeción de conciencia. En lo que nos interesa ahora hay que destacar que el criterio formal alude a los derechos fundamentales como los comprendidos en la Sección I del Capítulo II del Título I. El TC ya había utilizado de manera indiscriminada «derechos constitucionales» y «derechos fundamentales» ${ }^{13}$ y no parece bastarle con dicho criterio y ensaya una segunda fórmula, de carácter material, que combina con la primera al entender que es «un derecho constitucional reconocido por la Norma suprema en su art. 30.2, protegido, sí, por el recurso de amparo (art. 53.2), pero cuya relación con el art. 16 (libertad ideológica) no autoriza ni permite calificarlo de fundamental. A ello obsta la consideración de que su núcleo o contenido esencial -aquí su finalidad concreta- consiste en construir un derecho a ser declarado exento del deber general de prestar el servicio militar (no simplemente

\footnotetext{
${ }^{13}$ En la STC de 8 de Abril de 1981 (fund. 9 y 10) relativa al Derecho de huelga.
} 
a no prestarlo) sustituyéndolo, en su caso, por una prestación social sustitutoria» ${ }^{14}$. Destaca Cruz Villalón, en relación con lo anterior, dos elementos interesantes: en primer lugar que «los derechos fundamentales son una categoría dogmática del Derecho constitucional. Allí donde no hay Constitución (y habrá que ver si cualquier Constitución vale $)^{15}$ no habrá derechos fundamentales. Habrá otras cosas, con seguridad más importantes, derechos humanos, dignidad de la persona; habrá cosas parecidas, acaso igual de importantes, libertades públicas francesas, derechos públicos subjetivos alemanes; habrá, en fin, cosas distintas, como fueros o privilegios, pero no habrá derechos fundamentales ${ }^{16}$. En segundo lugar, y más importante respecto a nuestra labor en este punto, la identificación de los derechos fundamentales con los detallados en el Capítulo II del Título I de la C.E. ${ }^{17}$

Respecto a la primera afirmación creo que tiene razón Luis Prieto ${ }^{18}$ al rechazar esta visión no respetuosa con otros fenómenos jurídicos, con caracteres de derechos fundamentales que se plasmaron en textos diferentes a una Constitución. Es el caso de la Tercera República Francesa, cuyo conjunto de Leyes Fundamentales suplieron la labor de la Constitución a estos efectos, y dotó de un cuerpo de materias con virtualidad de derechos fundamentales y una eficaz custodia de las mismas a pesar de no contar con la parte dogmática de una Constitución. A través de libertades públicas, de derechos reconocidos, e incluso de construcciones jurídicas como los «principios fundamentales reconocidos por las leyes de la República $\gg{ }^{19}$ merced a la cadena de validez que en el tiempo se estableció con los preámbulos de las Constituciones de 1946 y 1958, fue posible reconocer derechos fundamentales -como el derecho de asociación

${ }^{14}$ STC 160/87, de 27 de Octubre, F.3.

${ }^{15}$ Vid. en este sentido Curso de Derechos Fundamentales (II). En colaboración con Rafael de Asís Roig y Ángel Llamas. En preparación. En el cap. II, «El sistema jurídico de los derechos fundamentales: los rasgos de su identificación», pág. 2 y ss. (del cap. II) en el original, Peces-Barba parece contestar dando los rasgos del Ordenamiento jurídico y por extensión a la Constitución para observar qué tipo de texto «vale» a estos efectos. Más adelante el autor discrepa de la identificación de derechos fundamentales como necesariamente constitucionales, pág. 6 (del Cap. II) en el original.

${ }^{16}$ Cruz Villalón, P., Formación y evolución de los derechos fundamentales. Ponencia publicada en Introducción a los Derechos Fundamentales Volumen I, Ministerio de Justicia, Centro de publicaciones de la Secretaría general Técnica, Madrid, 1988, pág. 162.

${ }^{17}$ Obra citada, pág. 161.

${ }^{18}$ Prieto, L., Estudios sobre derechos fundamentales. Obra citada, págs. 95 y ss.

${ }^{19}$ Vid. Peces-Barba, G., Libertad, Poder, Socialismo. Sobre la misma materia vid. Llamas, Á., Los principios fundamentales reconocidos en las leyes de la República, Revista de las Cortes Generales, núm. 15, Madrid, 1988. 
en famosa sentencia del 16 de Julio de 1971 o la libertad religiosa en materia educativa- a través de la capacidad que encontró el Conseil Constitutionnel en dicha fórmula catalizadora de verdaderos derechos fundamentales.

El segundo aspecto, de más interés ahora como veíamos, es el encasillamiento de los derechos fundamentales en su correcta sede. Cruz Villalón recoge dos dimensiones de los derechos fundamentales. Un concepto restringido, atendiendo a la reserva de ley orgánica que hace el art. 81.1 de la C.E., que circunscribe los derechos fundamentales a la Sección $1^{\text {a }}$. del Capítulo II. La sentencia sobre la LOAPA, STC 76/83 en su Fundamento jurídico 2 y la STC 160/87 sobre la Ley de Objeción de conciencia, en su Fund. jur. 3, corroboran esta visón restringida. La anfibológica utilización de la Constitución española de la categoría derechos fundamentales permite a este autor hablar de un concepto amplio, «que se aproxima más a su aparición en el epígrafe del propio Título. Puede adelantarse -añade Cruz Villalón- ya que cuantas veces aparece la expresión «derechos fundamentales» en nuestra doctrina constitucional sin conexión con el problema de la reserva de ley orgánica, el Tribunal Constitucional está operando con ese contenido más amplio de la expresión». Entre ambas concepciones la tesis sostenida finalmente atiende a los contenidos y a la fuerza o virtualidad que determinará considerar a los derechos fundamentales «en el sentido de nuestra Constitución, y con la sola reserva de sus significado más restringido en el artículo 81.1 CE, son los derechos contenidos en el capítulo II del Título I de la misma. En otras palabras, nuestros derechos fundamentales son, básicamente, los derechos y libertades que nuestra Constitución reconoce a lo largo de sus artículos 14 a $38 »{ }^{20}$. Desde la virtualidad o fuerza que acompaña a los derechos fundamentales los elementos definitivos serán «la tutela judicial y el respeto de su contenido esencial por el legislador. Hoy no hay derecho fundamental, que se precie de serlo, que no sea susceptible de tutela judicial y de limitar el poder legislativo. Tal vendría a ser, pues, el «contenido esencial» de los derechos como categoría» ${ }^{21}$.

De esta manera el contenido esencial se convierte en categoría definitiva para considerar los derechos fundamentales, ya que el artículo 53.1 circunscribe el respeto al contenido esencial a «los derechos y libertades reconocidos en el Capítulo segundo». Del mismo modo, que la tutela judicial no alcance a los «principios reconocidos en el Capítulo tercero» permite llevar a Cruz Villalón a fijar en el Capítulo II la sede de los derechos fundamentales. Un tanto arbitrariamente

\footnotetext{
${ }^{20}$ Cruz Villalón, Obra citada, pág. 160.

${ }^{21}$ Ibídem, pág. 161.
} 
sin embargo considerará que otras garantías, como la tutela judicial reforzada o la reserva de ley orgánica, no pasan de ser «contenido accidental» y no sustancial para la misma delimitación.

No es claro sin embargo el alcance de los principios recogidos en el Capítulo tercero, en cuanto que desprovistos, como decía nuestro autor, de tutela judicial. En primer lugar el art. 53.3 afirma: «el reconocimiento, el respeto y la protección de los derechos reconocidos en el Capítulo tercero informarán la legislación positiva, la práctica judicial y la actuación de los poderes públicos». Los jueces deben contar con ellos para las funciones de aplicación constitucional y además el Tribunal Constitucional puede apoyarse en ellos, desde el artículo 39 a 52 para declarar inconstitucional una ley. La posición en que el artículo 53.3 ha dejado a los principios del Capítulo III al establecer que «sólo podrán ser alegados ante la jurisdicción ordinaria de acuerdo con lo que dispongan las leyes que los desarrollen», conlleva una «rebaja» de su condición al aparecer necesitados del desarrollo oportuno. No obstante esta apariencia, García de Enterría afirma: «Es una expresión desgraciada, pero que claramente no puede interpretarse como una prohibición de alegación, y menos de aplicación, en el sentido que hemos visto, de tales principios por los tribunales ordinarios, interpretación que sería contradictoria con el párrafo inmediatamente anterior del mismo precepto, que hemos visto que impone -en la forma imperativa de futuro- que dichos principios «informarán la práctica judicial». Lo que, con toda claridad, pero con escasa fortuna, intenta decir el artículo es que al formular tales principios la Constitución no ha pretendido configurar verdaderos derechos fundamentales, sino principios propiamente dichos que han de orientar la acción del Estado como fines determinados de su misión; nada más ${ }^{22}$. Aquí curiosamente las interpretaciones de Cruz Villalón se entrecruzan con las de García de Enterría. El primero podría entender que los principios son derechos fundamentales, lo que no puede ser por su incapacidad de ser tutelados directamente, mientras que para el segundo, a pesar de su tutela efectiva por parte de Tribunales ordinarios y de la jurisdicción constitucional, no pueden ser considerados como derechos fundamentales. Efectivamente, García de Enterría da a los principios está capacidad». Cuando dice que esos principios se invocarán ante los tribunales de acuerdo con las leyes que los desarrollen, no quiere decir, aunque lo parezca, que el legislador sea absolutamente libre para interpretar y hacer aplicación de su arbitrio de tales principios; una declaración tan grave debería haber figurado para ser efectiva, como un límite a la declaración

\footnotetext{
${ }^{22}$ García de Enterría. E., La Constitución como norma y el Tribunal Constitucional. Obra citada, pág. 69.
} 
de inconstitucionalidad de las Leyes de desarrollo de tales principios, y esa limitación no consta en los artículos 161, 1, a), 163 y 164, antes bien la definición de la inconstitucionalidad en términos puramente formales, que incluye la infracción de todos y cualquiera de los artículos de la Constitución, sin excepción posible» ${ }^{23}$. La interpretación de García de Enterría incide así sobre el Tribunal Constitucional y también sobre los Tribunales ordinarios. Sobre el primero porque el TC puede declarar inconstitucional una Ley por infracción de los principios del Capítulo III, si por ejemplo la Ley 11/1981, de 13 de mayo, que modifica el Código Civil en materia de filiación, patria potestad y régimen económico del matrimonio, no permitiese la investigación de la paternidad, frente al art. 39.2. Respecto al Juez ordinario lo anterior quiere decir que también él mantiene lo que le permite el art. 163 de la C.E., mediante la interposición de cuestión ante el Tribunal Constitucional cuando se tenga duda razonable sobre tal inconstitucionalidad respecto a los principios recogidos entre los artículos 39 y 52.

Este sentido de depuración de carácter negativo se hace más complejo si tenemos en cuenta que bajo la acepción de «principios rectores de la política social y económica» no aparecen sencillamente normas programáticas o «determinaciones de fines del Estado» (o Staatszielbestimmmungen de los constitucionalistas alemanes), sino además una pluralidad de derechos, garantías, instituciones jurídicas, normas secundarias que explicitan los desarrollos necesarios y la vinculación de los poderes públicos a determinadas líneas de actuación. Esto ocurre en la propia Sección $1^{\mathrm{a}}$. del Capítulo II, donde, a pesar de la protección especial, de la tutela judicial indubitada y la necesidad de regularse el ejercicio de los derechos y libertades por ley, cuenta con una base sobre la que descansan elementos heterogéneos. Así L. Martín-Retortillo, al hablar de la confluencia en las Constituciones de elementos orgánicos y elementos dogmáticos, estima: «Esta mezcla de elementos heterogéneos, insisto, no es ninguna novedad. Y el fenómeno se va a repetir una vez más en la sección $1^{\mathrm{a}}$. hay allí reglas constitucionales, sin más (por supuesto que el derecho fundamental como derecho objetivo o como institución también es regla constitucional, pero es algo más). Hay, también, principios constitucionales o principios generales del derecho, hay normas, ya sean de acción o de organización; hay criterios organizativos o principios de orden; hay garantías institucionales, en el sentidos acuñado por Carl Schmitt; garantías procesales, etc. En resumen, hay muchas cosas. Y, dada la fluidez y riqueza de los actuales ordenamientos jurídicos, hay que decir que de alguna de estas otras cosas

${ }^{23}$ Ibídem, pág. 70 . 
-distintas de los derechos fundamentales- pueden también derivar en ocasiones titularidades subjetivas, derechos subjetivos en algún caso» ${ }^{24}$. En consecuencia la labor de delimitación que realiza el TC, se ha producido en sentencias como la 83/1984, que trata sobre el art. 36 de la C.E., estimando que la reserva específica -de ley que debe respetar el contenido esencial- es bien distinta de la que respecto de los derechos y libertades se contiene en el art. 53.1 de la Constitución, y entiende que no puede oponerse el respeto a ningún contenido esencial de derechos y libertades «que en ese precepto no se proclaman» ${ }^{25}$. Todo ello nos permite entender la incorporación de los principios rectores de la política social y económica desde un punto de vista menos alejado del resto de los derechos y libertades en su aplicación por parte de los tribunales, dado que algunas de las características aducidas para rebajar su condición jurídica, desde el punto de vista de la identificación previa a la tutela efectiva, no parecen ser tan definitivas.

Y no sólo ocurre desde el punto de vista negativo en la posibilidad de la cuestión que permite el art. 163 de la C.E. a los Tribunales ordinarios. García de Enterría destaca el catálogo de funciones que en este aspecto son plenamente aplicables a los principios del Capítulo III: «El carácter normativo de la Constitución vincula inmediatamente a la totalidad de los jueces y Tribunales del sistema y no sólo al Tribunal Constitucional, y que esa vinculación directa incluye las siguientes necesarias aplicaciones de la norma suprema, que ha de entenderse que se incluyen entre las funciones preceptivas a que les obligan los principios de sometimiento «al imperio de la Ley» (art. 117, 1 de la Constitución) y iura novit curia ${ }^{26}$.

Con este bagaje ${ }^{27}$, el juez ordinario puede aplicar con plenitud de

${ }^{24}$ Vid. Martín-Retortillo, L., Régimen constitucional de los mentales. Citado, págs. 85 y s.

${ }^{25}$ En el mismo sentido la STC 86/1982 respecto al art. 20 de la C.E. no reconoce ningún derecho ni libertad, ni admite por tanto contenido esencial previo a la regulación de los medios de comunicación social.

${ }^{26}$ García de Enterría, E., La Constitución como norma y el Tribunal Constitucional. Obra citada, pág. 67.

${ }^{27}$ Me refiero a las funciones preceptivas por todos conocidas y que García de Enterría destaca (Ibídem, pág. 67):

-enjuiciamiento previo de la constitucionalidad de las leyes antes de su aplicación a los dos efectos que inmediatamente se precisan:

-juicio de posibilidad de inconstitucionalidad de la Ley aplicable al proceso como resultado de dicho enjuiciamiento previo, supuesto en el cual el juez o Tribunal de que se trate deberá plantear la cuestión ante el Tribunal Constitucional;

-juicio positivo de constitucionalidad de la Ley aplicable al proceso, como resultado del mismo enjuiciamiento previo, juicio positivo que condiciona cualquier aplicación de cualquier Ley; 
competencia los «principios rectores de la política social y económica» así como cualquier precepto de la Constitución en función de la vinculación normativa de cada norma constitucional. El ejercicio de la función de aplicación constitucional comprendería a nuestros efectos para comprometer a los Tribunales ordinarios y Tribunal Constitucional igualmente cada uno de los puntos arriba citados.

Queda la posibilidad de considerar a los principios como ajenos al carácter jurídico de otros preceptos constitucionales por «necesitar además que tenga estructura lógica de norma jurídica; es decir, que consista en un mandato, una orden, prohibición o correlativa delimitación de esferas jurídicas entre sujetos, con establecimiento de recíprocas obligaciones y derechos. Intentando, pues, de nuevo resumir nuestras afirmaciones: es la estructura lógica de la norma la que, en definitiva, diferencia al Derecho de la retórica ${ }^{28}$. J. L. Serrano realiza la distinción entre el carácter de derecho subjetivo -que niega a los principios a pesar de lo establecido en el art. 162 y su alegación ante el Tribunal Constitucional fundamentando un recurso de inconstitucionalidad- y el carácter normativo de un precepto constitucional, por cuanto recuerda frente a la posición de Garrido Falla, de Martínez Calcerrada, de Ruiz Vadillo o de Martínez Morán ${ }^{29}$, su segunda condición. La clave estará para este autor en considerar que los principios rectores de la política social y económica funcionan -y aquí sigue las tesis de Kelsen- como normas jurídicas de carácter dependiente o no autónomas ${ }^{30}$. No vamos a extendemos más sobre otras visiones ni profundizar sobre ésta, pero sólo hacer hincapié en el carácter tutelable de los principios referidos bien siguiendo las tesis de la función asimilable a la protección determinados derechos subjetivos, por su protección judicial, por los criterios extensivos del TC, sobre los que hablaremos en el punto siguiente, o como meros preceptos constitucionales, autónomos o dependientes de libertades o derechos fundamentales, protegidos por la disposición derogatoria tercera de la C.E. y el art. 9 de la misma.

Una aproximación garantista a las fuentes de los derechos... 707

-juicio de inconstitucionalidad de Reglamentos, como previo a cualquier aplicación de los mismos, con la consecuencia de la inaplicación pura y simple de los Reglamentos que se estimen inconstitucionales (aparte de ilegales) (...);

-juicio de inconstitucionalidad de los actos jurídicos públicos (administrativos, judiciales) y privados y negación de la validez de esos actos concluya en su inconstitucionalidad; -interpretación conforma a la Constitución de la totalidad del ordenamiento, tanto de Leyes como de Reglamentos.

${ }^{28}$ Garrido Falla, F., Comentarios a la Constitución, Civitas, Madrid, 1980, pág. 579.

${ }^{29}$ Vid. Serrano, J. L., Algunas hipótesis sobre los principios rectores de la politica social y económica, Revista de Estudios Políticos, no. 56, Abril-Junio 1987, pág. 102 y nota 17.

${ }^{30}$ Ibídem, pág. 104. 


\section{La fuente de los derechos fundamentales desde la visión garantista}

De lo anterior podemos sacar dos conclusiones provisionales. En primer lugar es necesario acudir a las garantías de los derechos fundamentales para poder establecer correctamente el alcance de la delimitación y la fuente de los derechos fundamentales. Cuando Peces-Barba establece el primero de los criterios de distinción por las fuentes rompe el compartimento estanco que distingue este criterio del de las garantías. Peces-Barba sintetiza: «De acuerdo con el primero [criterio de distinción por las fuentes] cabe distinguir entre los derechos del capítulo segundo, que se ven afectados por el precepto contenido en el número primero del artículo 53, y que, en consecuencia, «sólo por ley, que en todo caso deberá respetar su contenido esencial, podrá regularse el ejercicio de tales derechos y libertades...»y aquellas otras libertades o derechos que no se hallan sometidos a esta rigurosa cláusula y que por lo tanto pueden obtener un desarrollo de otra naturaleza. A su vez, la división del capítulo segundo en dos secciones halla su justificación en el artículo 81, según el cual los derechos fundamentales y las libertades públicas forman parte del ámbito propio de la Ley Orgánica» ${ }^{31}$. El criterio de distinción estricto en función de las garantías será definitivo para ver el grado de «resistencia» o de fortaleza de los derechos fundamentales y su adecuada caracterización respecto a los niveles de identificación relevantes para las fuentes de los derechos fundamentales. Como consecuencia de esta tesis, Luis Prieto establece un primer eslabón en donde identifica derechos fundamentales con los derechos constitucionales: «Si renunciamos a una concepción esencialista del lenguaje, si abandonamos la vieja idea de que entre las palabras y las cosas existe algo así como un nexo metafísico, el problema se reduce sencillamente a explicar el uso que hacemos de los enunciados jurídicos. Por ello, si se advierte, no existe ningún obstáculo lógico ni empírico para decir que derechos fundamentales son todos los reconocidos por la Constitución, los que así aparecen rubricados, los que gozan de recurso de amparo, los que han de regularse por ley orgánica, etc. Inclinarnos por una u otra posibilidad depende tan sólo de la utilidad que cada una de ellas nos proporcione para una mejor comunicación. (... ) Pero al menos en nuestro ordenamiento, sí creo que la mejor noción jurídica de derechos fundamentales es precisamente aquella que les identifica con los derechos constitucionales» ${ }^{32}$. El paso siguiente no es coherente con lo anterior puesto que los grados

31 Falta el texto.

${ }^{32}$ Luis Prieto, Estudios sobre derechos fundamentales, pág. 103. 
siguientes de resistencia se circunscribirán al Título Primero en su estudio, y no a todos los derechos constitucionales-fundamentales. Ni siquiera, haciendo uso de su observación de no acudir a razones metafísicas, respetando el lenguaje propio de la Constitución en alguno de los epígrafes que aluden a los derechos fundamentales, o el más amplio del Título Primero. La «distinta resistencia de los derechos constitucionales» se convierte no obstante en la gradación de la protección de los derechos no constitucionales sino del Título Primero, tesis que Luis Prieto afronta por la vía de hecho, que creo es la más adecuada, pero que no coincide con lo anteriormente mantenido. En las tesis de L. Martín-Retortillo no ocurre lo mismo. Se mantiene un criterio de identificación de los derechos fundamentales según su «cualificación» o «garantía reforzada» y por tanto restringiéndose a los derechos incluidos en la Sección $1^{\text {a }}$. del Capítulo II. En las tesis definitivas propone la posibilidad de hablar de los derechos fundamentales en otros términos dependiendo de su ubicación concreta fuera de esta Sección pero en todo caso respetando el núcleo esencial de los que están identificados por su «garantía reforzada» ${ }^{33}$.

En uno y otro caso nuevamente son las garantías, con independencia de los futuros problemas de interpretación o de coherencia con el «iter» de la propia exposición, lo que nos lleva a establecer el sistema de fuentes, dada la primera identificación.

Los diferentes grados de resistencia nos permite hablar de tres clases de derechos. En primer lugar los derechos y libertades comprendidos en el Capítulo II, caracterizados por lo que entiende el art. 53.1 «sólo por ley, que en todo caso deberá respetar su contenido esencial, podrá regularse el ejercicio de tales derechos y libertades». El art. 81.1 especifica además la necesidad de ley orgánica para el desarrollo de derechos fundamentales y de las libertades públicas». Especialmente la sección primera de este capítulo, que según el art. 53.2 engloba aquellos derechos y libertades que junto al art. 14 pueden ser alegados para recabar tutela «ante los tribunales ordinarios por un procedimiento basado en los principios de preferencia y sumariedad y, en su caso, a través del recurso de amparo ante el Tribunal Constitucional. Este último recurso será aplicable a la objeción de conciencia reconocida en el art. 30».

A continuación estarían los derechos de la sección $2^{\mathrm{a}}$. del Capítulo II, en donde se encuentra una pluralidad de derechos, establecimiento de deberes, garantías de corte económico, tributario y laboral -con derechos al trabajo y a la negociación colectiva, de fundación, de propiedad y de empresa- así como derechos de corte individual

\footnotetext{
${ }^{33}$ Régimen constitucional de los derechos fundamentales. Obra citada, pág. 81 .
} 
como la objeción de conciencia. Además se recogen remisiones a la ley y finalidades de actuación para los poderes públicos, cercanos a los que están incluidos en el capítulo III con el epígrafe de «principios rectores de la política social y económica». Entre estos últimos y los derechos del capítulo I existe una última gradación, ya que aunque la Constitución no estima el «grado de resistencia» de estos derechos (11 a 13, con declaración formal de los elementos de la nacionalidad y su remisión a la ley, sin entrar en las formas de adquisición y pérdida de la nacionalidad) tampoco les niega la capacidad de ser alegados ante la jurisdicción ordinaria «de acuerdo con lo que dispongan las leyes que los desarrollen» (art. 53.3 de la C.E.).

Sobre este último eslabón de los derechos fundamentales caracterizados por su «fortaleza jurídica» ya hemos hablado en el punto anterior de este estudio. Es cierto que están afectados por lo indicado en la última parte del art. 53.3. Tan sólo recordar, además de la capacidad de «informar la legislación positiva, la práctica judicial y la actuación de los poderes públicos»y y lo establecido por el principio de vinculación normativa de la Constitución a efectos de aplicación por los Tribunales ordinarios y Constitucional, lo indicado por la jurisprudencia constitucional. Es realmente significativa la sentencia 186/81 de 2 de Febrero en cuyo fundamento jurídico 1.B se entiende: «... entendemos que los principios generales del Derecho, incluidos en la Constitución, tienen carácter informador de todo el ordenamiento jurídico -como afirma el art. 1.4 del título preliminar del Código Civil-, que debe ser así interpretado de acuerdo con los mismos. Pero es también claro que allí donde la oposición entre las leyes anteriores y los principios generales plasmados en la Constitución sea irreductible, tales principios en cuanto forman parte de la Constitución, participan de la fuerza derogatoria de la misma, como no puede ser de otro modo. El hecho de que nuestra norma fundamental prevea en su artículo 53.2 un sistema especial de tutela de las libertades y derechos reconocidos -entre otros en el artículo 14, que se refiere al principio de igualdad- no es sino una confirmación de carácter específico del valor aplicativo, y no meramente programático, de los principios generales plasmados en la Constitución. (... ) En conclusión, en los supuestos en que exista una incompatibilidad entre los preceptos impugnados y los principios plasmados en la Constitución, procederá declararlos inconstitucionales y derogarlos por opuestos a la misma» ${ }^{34}$. De este modo la

\footnotetext{
${ }^{34}$ Vid. García Martínez, Ma . A., Algunos aspectos de nueve años de jurisprudencia constitucional, Revista de la Facultad de Derecho, Universidad Complutense, nº. 76, Madrid, 1991. Especialmente págs. 483 y ss. También sobre los principios en la elaboración jurisdiccional constitucional Rubio Llorente, F., La jurisdicción constitucional de creación de Derecho, Revista Española
} 
protección

de Derecho Constitucional, Año 8, $\mathrm{n}^{\circ}$. 22. Enero-Abril 1988. Para determinados principios desde el punto de vista del Derecho comparado y su tratamiento en págs. 44 y ss. También García Canales. M., Principios generales y principios constitucionales, Revista de Estudios Políticos (Nueva época), No. 64, Abril-Junio 1989. Especialmente págs. 149 y ss. También, para un repaso más descriptivo, De Esteban, J., Apuntes de Derecho Constitucional Español. Servicio de Publicaciones de la Facultad de Derecho de la Universidad Complutense de Madrid, Tomo II, Principios del régimen constitucional español. 
delimita dentro de este Capítulo una parte de los derechos fundamentales que en el grado más bajo de su protección sin embargo tienen, como hemos visto, una eficacia plena.

\section{El sistema mixto}

Las fuentes de los derechos fundamentales aparecen en el ordenamiento jurídico español dentro de la Constitución y bajo el que podemos denominar «sistema mixto» ${ }^{35}$. Los derechos fundamentales, a la luz del texto constitucional y en coherencia con lo visto anteriormente aparecen dentro del Título primero de la Constitución «De los derechos y deberes fundamentales», que comprende desde el artículo 10 al artículo $55^{36}$. El Título se divide en un artículo previo

${ }^{35}$ En denominación utilizada para las fuentes de los derechos fundamentales por Peces-Barba en Derechos fundamentales, Latina Universitaria, Madrid, $3^{\mathrm{a}}$. ed., 1980 (1 ${ }^{\mathrm{a}}$. ed. 1973), págs. 138 y ss. en general y 162 y ss. entre otras para este tema. Pérez Luño lo utiliza, en el mismo contexto, de forma diferente al describir una Constitución que enuncia grandes principios o postulados sobre derechos fundamentales y que los concreta después en normas específicas en el propio texto constitucional. Los Derechos Fundamentales. Obra citada, pág. 58.

${ }^{36}$ Aunque no es el objeto de este trabajo recoger diferentes sistematizaciones, es necesario hacer alusión a la delimitación sistemática que realiza Pérez Luño. En la C.E. aparece a través de cinco instrumentos de positivación:

1. Valores superiores del orden jurídico-político constitucional. Son los derechos fundamentales del Preámbulo de la Constitución representando los valores básicos en sentido análogo a los que la doctrina germana considera Grundwerte, y que conectan con los valores de una mayoría de ciudadanos en el orden jurídico-político. Están directamente relacionados con los valores del art. 1.1 de la C.E. «como valores superiores de su ordenamiento jurídico la libertad, la justicia, la igualdad y el pluralismo político» y aunque Pérez Luño lo añade en la segunda de las categorías que ahora veremos, parece que es más adecuado hablar en esta primera del art. 10.1 de la C.E., al extraerse de la dignidad humana los propios valores superiores y hacer partir de ella los demás principios del Título Primero «De los derechos y deberes fundamentales».

2. Principios constitucionales. Delimitan el marco político, social y, económico que va a «determinar las modalidades de ejercicio de todos los derechos fundamentales, como también una serie de postulados encaminadas a orientar la acción de los poderes públicos». La base de su operatividad está en el art. 9.2: «Corresponde a los poderes públicos promover las condiciones para que la libertad y la igualdad del individuo y de los grupos en que se integra sean reales y efectivas, remover los obs- 
y está estructurado en torno a cinco capítulos. El primero «De los españoles y los extranjeros», abarca los artículos 11 a 13. El Capítulo segundo, «Derechos y Libertades», con el artículo 14 que sirve de introducción a las dos secciones siguientes: «De los derechos fundamentales y de las libertades públicas» y la segunda, «De los derechos y deberes de los ciudadanos». La primera de las dos secciones comprende desde el artículo 15 al 29, y la segunda los artículos 30 a 38. El Capítulo tercero, tiene como epígrafe «De los principios rectores de la política social y económica» y sus artículos van desde el 39 al 52. El Capítulo cuarto se denomina «De las garantías de los derechos y libertades fundamentales», y cuenta con los artículos 53 y 54. El Capítulo quinto, «De la suspensión de los derechos y libertades», contiene el artículo 55.

El art. 53 establece que sólo por ley podrá regularse el ejercicio de los derechos y libertades reconocidos en el Capítulo segundo del Título Primero. A su vez, el artículo 81.1 define como leyes orgánicas «las relativas al desarrollo de los derechos fundamentales y de las libertades públicas...». Parece adecuado interpretar por tanto que la ley orgánica es preceptiva para los derechos y libertades contenidos en la Sección primera del Capítulo II, así como para regular la institución del Defensor del Pueblo (art. 54 C.E.), mientras que basta la ley ordinaria, que debe respetar el «contenido esencial», para el resto del Capítulo II del Título primero. Los mejores argumentos a

táculos que impidan o dificulten su plenitud y facilitar la participación de todos los ciudadanos en la vida política, económica, cultural y social». El artículo 10, tendría en la dignidad de la persona una de las bases, como decíamos, en la categoría anterior pero los principios que le siguen se vinculan con el orden político y la paz social y además aparece como vía de interpretación «la Declaración Universal de Derecho Humanos y los tratados internacionales sobre las mismas materias ratificados por España» (art. 10.2). Los «principios rectores de la política social y económica» del Capítulo III quedarían aquí englobados con el alcance que hemos estudiado en este trabajo.

3. Cláusulas generales. Lo forman el grupo de derechos fundamentales que acogidos en el articulado de la Constitución y positivados no como principios ni valores sino como derechos, se hallan remitidos a la legislación orgánica para la delimitación de su alcance y contenido. Así el art. 17.4, el 18.4, el 20.3, el 24.2, el 28.2, etc.

4. Normas específicas o casuísticas. Desde la Constitución se establecen una serie de derechos de forma pormenorizada que no exigen desarrollo posterior, sino que su alcance y significación reside en el propio precepto constitucional. Así el art. 14 o el art. 26.

5. Normas de tutela. Existen también las normas dirigidas a la garantía de los derechos fundamentales, como los artículos comprendidos en el Capítulo IV del Título Primero, o los artículos 161 ó 163 de la C.E.

Desde esta aproximación sistemática podemos entrar en la descripción de los datos que, para observar el sistema de fuentes, ofrece la Constitución. De manera complementaria con la base organizativa que parte para las fuentes del art. 5.3. Pérez Luño, A., Los derechos fundamentales. Obra citada, págs. 58 y ss. 
favor de esta interpretación están a mi juicio, en la similitud de la terminología utilizada en el art. 81.1, coincidente con el epígrafe de la Sección Primera, y la incoherencia, por otro lado, que hubiera supuesto mantener la ley orgánica con carácter expansivo respecto a todo el Capítulo II, mientras el art. 53.1 afirmase que el ejercicio de los derechos y libertades del capítulo II se regulan por ley. La alternativa de haber podido incluir la especificación de ley orgánica en el art. 53.1 o incluso haber suprimido esta especificación y haber sido genérica desde el art. 81.1, excluyen otra interpretación ${ }^{37}$. En esta línea argumental que utiliza Luis Prieto se añade además un criterio de valoración del significado político de las leyes orgánicas por parte del Tribunal Constitucional. La STC 5/1981, de 13 de febrero entiende: «... la concepción formal de la ley orgánica podría producir en el ordenamiento jurídico una petrificación abusiva en beneficio de quienes en un momento dado gozasen de la mayoría parlamentaria suficiente y en detrimento del carácter democrático del Estado» ${ }^{38}$; o en STC $76 / 183$, de 5 de agosto considerando las exigencias de mayorías cualificadas con «carácter excepcional» ${ }^{39}$.

Si bien la primera parte de la línea argumental me parece adecuada para resolver las posibles interpretaciones no coincidentes, la manifestación del TC me parece un tanto ajena a su propia labor. El enjuiciamiento en función de las consecuencias en esa dimensión nos alejan del lugar que debe presidir una línea jurídica en coherencia con los argumentos técnicos. La búsqueda del carácter democrático restringiendo las posibilidades de una ley orgánica -como si sus supuestos no exigieran una mayor participación en su mayoría cualificada- parece quedar un tanto fuera de cuestión en la argumentación del $\mathrm{TC}^{40}$. El resultado, sin embargo incide sobre la consideración restringida del uso de la ley orgánica.

${ }^{37}$ En línea argumental con lo expuesto por Luis Prieto en Estudios sobre derechos fundamentales, pág. 180.

${ }^{38}$ Fund. jur. 21.

${ }^{39}$ Fund. jur. 2.

${ }^{40}$ No siempre la cautela respecto a los refuerzos de normas protegidas por procedimientos de mayorías cualificadas implica una posición democrática como alternativa. Recuerda en cierto sentido las opiniones de Carl Schmitt cuando atacaba a las materias reservadas con cualificación de la parte dogmática de la Constitución de Weimar (1919) en su obra Legalität und Legitimität, Duncker \& Humblot, Munich y Leipzig, 1932. Versión castellana: Legalidad y Legitimidad, Aguilar, Madrid, 1971. (Apartado reservado al legislador ratione materiae). O respecto a la calificación de «tiranía de los valores» para la «petrificación» de valores que por su aprobación cualificada se reforzaban y se imponían a mayorías simples posteriores rompiendo la regla de las mayorías (En Die Tyrannei der Werte. En Skäularisation und Utopie, Ebracher Studien, Festschrift für Ernst Forsthoff, W. Kohlhammer Verlag, Stuttgart, 1967. Manejado en la versión italiana La tirannia dei valori, Antonio Pellicani Ed., Roma, Apartado I y III). Los análisis y planeamientos del 
En el texto constitucional aparecen un grupo de derechos con un desarrollo considerable; así el art. 17 sobre el derecho a la libertad y a la seguridad, en el 17.2, el art. 18 en la garantía del derecho al honor -18.1, 18.2 y $18.3-$, el art. 19 sobre libertad de residencia y de circulación -19.1 , el art. 20.1, 20.2 y 20.5 sobre libertad de pensamiento y de expresión, art. 21 sobre el derecho de reunión, el art. 22 sobre el derecho de asociación, el art. 23.1 sobre el derecho de participación en asuntos públicos, el art. 24 sobre la tutela efectiva de los jueces y tribunales, o el art. 25 sobre el principio de legalidad y de irretroactividad de las normas.

Las remisiones a la ley, que caracterizan esta fórmula de desarrollo del sistema mixto encuentra en el texto constitucional importantes ejemplos. El art. 17.3 sobre la asistencia letrada al detenido, desarrollado por LO 14/1983 y LO 4/1981, el art. 17.4 sobre el procedimiento de «habeas corpus» desarrollado por LO 6/1984, de 24 de mayo, el art. 18.4 sobre el uso de la informática en garantía del honor y la intimidad personal y familiar desarrollado por LO 7/1984, de 15 de octubre y LO 5/1992, de 25 de octubre, el art. 20.3, sobre la regulación de la organización y el control parlamentario de los medios de comunicación social dependientes del Estado, desarrollado por Ley 4/1980, de 10 de enero, por Ley 46/1983 de 26 de diciembre y ley 10/1988 de 3 de mayo (en este caso ya sobre Televisión privada), el art. 20.4 sobre los límites de los derechos y libertades del art. 20 que entran en conflicto con otros derechos fundamentales, desarrollado por LO 1/1982, de 5 de mayo, el art. 23.2 sobre la igualdad en el acceso a funciones y cargos públicos, el art. 27 sobre el derecho a la educación, desarrollado por LO 8/1985, de 3 de junio, el art. 29 sobre el derecho de petición individual o colectiva, cuya Ley 92/1960 de 22 de diciembre sigue parcialmente vigente y el art. 30.2 desarrollado por ley 48/1984, de 26 de diciembre y sobre recursos LO 14/1985, de 26 de diciembre, modificada por LO 14/1985 de 9 de diciembre.

El paso siguiente supone la conexión del sistema mixto con el contenido esencial del art. 53.1, básico en la concepción garantista, pero que exige un tratamiento pormenorizado que rebasa el marco del presente trabajo.

gran autor, aunque acertada en el diagnóstico político, tenía como consecuencia una propuesta de carácter antidemocrático que no hace falta, por conocida, comentar aquí. 
$\triangle \quad$ DOXA 15-16 (1994) 